\title{
Montessori Project
}

Lucy Mendoza ${ }^{2}$ and Andres Escamilla ${ }^{1}$,Ana Cristina García-Luna Romero ${ }^{3}$

${ }^{1}$ Universidad de Monterrey, Av. Ignacio Morones Prieto 4500, Zona Valle Poniente, 66238 San Pedro Garza García, N.L ${ }^{2}$ Universidad de Monterrey, Av. Ignacio Morones Prieto 4500, Zona Valle Poniente, 66238 San Pedro Garza García, N.L

${ }^{3}$ Universidad de Monterrey, Av. Ignacio Morones Prieto 4500, Zona Valle Poniente, 66238 San Pedro Garza García, N.L

\begin{abstract}
The architectural character of a building is based on different aspects. In order to understand the spirit of each building, we must study functional, associated and personal elements of it. Each architectural element differs in each aspect since each one is based on previous analysis and studies to be able to emerge and reach its purpose.
\end{abstract}

The Montessori architectural project is based on research on the method of this system that provides environments prepared for the proper development of children in education. The classrooms, materiality, socialization, environments and spaces are studied in order to be able to generate and gradually form design ideas to generate the project in a successful way.

It is decided based on the information obtained by previous studies, to use the neuroarchitecture design guideline to be able to meet the guidelines and objectives of this Montessori method, since this guiding concept goes beyond the study of space, but involves the emotions and feelings of the people who live the spaces. In this way, it is better understood that what guides us to the architectural design of the proposal based on the Montessori method are the studies of neuroarchitecture.

\footnotetext{
${ }^{1}$ Corresponding author Andres Escamilla: andres.escamilla@udem.edu

${ }^{2}$ Corresponding author Lucy Mendoza: 1ucy.mendozar@udem.edu

${ }^{3}$ Corresponding author Ana Cristina: ana.gacrcialuna@udem.edu
} 


\section{The character of a building}

Every building is different. [1] In order to understand that each person is actually different, the different characters that make up it must be analyzed. First, the functional characteristics of the building should be analyzed [1]. This element means that every building is built for some reason, that is, it has a specific function and purpose. This purpose is defined by the interior itself, which is coordinated with the exterior facade and therefore plays an important role in its design and structural function.

Relevant characteristics of buildings are another research topic for understanding architectural design and style. This refers to everything related to some influence. [1] These influences are based on historical and cultural studies and play an important role in determining the relevant characteristics of the structure. For this feature, you can refer to the recognition of the building, because it has features related to specific things, therefore, the building is dominated by this element to form the final architectural design feature.

Finally, it is understandable that each building has a spirit, a unique essence, and each living space and personality are different. [1] When designing architectural elements with an appropriate spirit, characteristics such as vitality, dignity, and elegance are expressed as important components of structural elements. From this essence, people begin to understand the anatomical structure of building design.

\section{The Montessori Method}

The Montessori Method was created by Dr. María Montessori [2], educator and pedagogue, who participated as an activist in defense of the rights of women and children, incorporated pedagogical methods to improve the learning and education of children with disabilities and from there, she had the idea of building environments that were pleasant and suitable for any child to promote the development of their intellectual and social skills.

María Montessori observed that for a child to pass from infancy to adulthood, it goes through 4 periods called "development plans" [2]. These periods have very different characteristics, but they constitute the foundations of successive stages. This refers to what the pedagogue describes as "the butterfly and the caterpillar are very different, but the butterfly is a consequence of its life in the caterpillar state and cannot come from the imitation of the example of another butterfly. To build the future it is necessary to watch over the present. The more we take care of the needs of one period, the more successful the next period will be "(La Mente Absorbente, María Montessori, Editorial Diana, 1998, p. 245). [3]
Development plans are divided according to age [3]. The first is the stage of birth until the child is 6 years old. This stage is characterized by "absorbing the child's thoughts", that is, the child sees himself as a sponge and absorbs all aspects of the surrounding environment. Then there are children from 6 to 12 years old, who are eager to explore the "rational thinking" plane of the world with their own thoughts and imagination. As the third plane, there is "humanistic thinking", that is, when children are 12 to 18 years old, that is, they are already in puberty, they want to understand human nature and the contributions that can be made before the emergence of society. Finally, when human beings are between 18 and 24 years old and have grown up and are eager to explore the world to fit their position, they will find "expert thoughts".

The main feature of the Montessori research method is to provide a prepared environment for children of any age, thereby providing intelligent work opportunities to take care of the small community. The constituent elements are classified according to order, aesthetics, simplicity and materiality, and children's education is carried out in the best way [3]. The classroom integrates age groups under 3 years, and promotes socialization, respect and unity from an early age.

This teaching model attempts to provide children with free opportunities to create a universal design environment that is best for any user [3]. The Montessori environment is defined as a spacious, well-organized and beautiful place, and every element that composes it has a reason to promote the good education of children. The environment is designed with furniture suitable for children, because the shelves, chairs and tables are tailor-made for children, so they feel comfortable, and from their point of view, they create a sense of belonging.

Independence and freedom are part of the ultimate goal of the model concept. According to Montessori analysis, it is hoped that as the child grows and develops, there will be less and less intervention [3]. This refers to the fact that children will not be alone, but will be accompanied by adults and teachers, but in this way, students can act and think on their own, build and develop self-confidence and self-discipline.

\subsection{Classrooms and spaces}

In order to provide a space that is truly suitable for the purpose of the Montessori education method, it is necessary to understand users (i.e., children) in the same way [3]. People recognize the evolutionary needs and characteristics of children of all ages, so they can create a "material and spiritual" good environment for them. Because children need to adapt to their environment and grow up, it is necessary to give a reason, a feeling of everything around them, so that they can have this sense of belonging, identity and relationship with them. That space. 
The best space for students to learn is closely related to children's prior analysis. Study colors, materials, textures and different elements to achieve the final design goals. The importance is designed by scientists who pay attention to the evolution of children's interest in manipulating objects, thereby developing knowledge and abstract thinking. Its design materials allow children to explore freely with a positive attitude, help focus and promote the learning process.

The classroom is subdivided according to the theme, and freedom of movement is realized [3]. Children are free to work individually or in groups, and respect each other's work style and rhythm from an early age. Each student is also self-disciplined when using materials. They take them from the shelf and return them so that others can use them. The same freedom enables children to find activities that meet their evolutionary needs.

The same classrooms are formed in 3 areas depending on the ages of the children ranging from under 3 years old, from 3 to 6 years old, from 6 to 9 years old and from 9 to 13 years old [3]. This is to give a more specialized approach to students and thus generate spaces that are suitable for their learning and are complements for the promotion of their education. The spaces still divided by age also favour the cooperation of students and the desire to learn, respect and the incorporation of educational knowledge.

\section{Landing concepts: architectural design}

The Montessori educational model is used to design the project's space based on internal and external architectural design. [4] According to the Master's degree in collective housing architecture issued by the Technical University of Madrid and the Swiss Federal Institute of Technology in Zurich, the design is a discipline whose focus is to meet the needs of creating habitable spaces using various elements, especially creativity. It is a combination of design and solution, aimed at analyzing and designing the space, while considering and determining the characteristics to be studied in order to achieve the project that meets the requirements, thereby forming the final overall architectural design.

For the realization of our proposal towards the Montessori Project, the main concept is the architectural design. Design, as mentioned above, is a mixture of different solutions and therefore an analysis is made to complement this basic concept according to the information of the character of a building and the meaning of the Montessori method.

We decided to take all the ideas of the conceptualization previously analyzed into consideration in order to be able to derive 4 items as a supplement to the main design elements. Combining these components is to achieve the goals of the Montessori method, provide accessible spaces that meet the needs of students, and promote education and support on various topics to follow the method. Next, a schematic diagram is shown, which represents the four complementary concepts of the main elements of the project, which will be explained in more detail to better understand their use and adaptability to the design.

Fig. 1 Conceptualization of the Montessori Project.

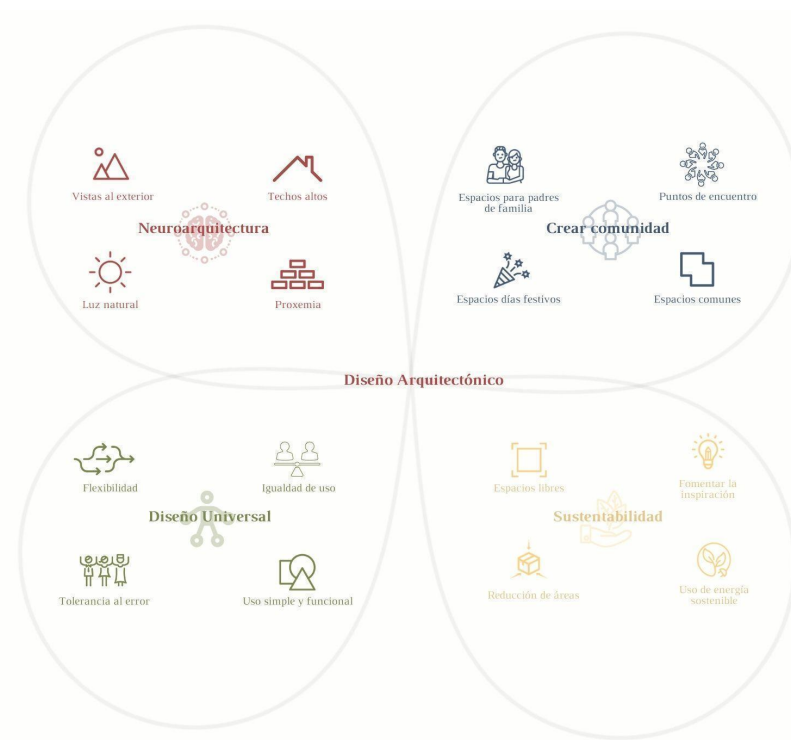

We start with the first project or component that is closely related to architectural design, namely Neuroarchitecture. According to Cristian Monroy, a social psychology consultant applied to marketing, neural architecture is a branch of neuroscience that studies the nervous system. Its purpose is to analyze and study architecture and its influence on human emotions [5]. The author commented that through emotional design, rules have been established to design and develop spaces to improve our happiness and reduce stress and anxiety.

The goal of neural architecture is to generate comfort in areas where users feel comfortable and encourage their emotions [5]. We take this element as an indispensable project to provide students with a suitable space to connect with their emotions, and because of the sensory emotions provided by the project, the project has successfully become a field that promotes education.

In order to generate neuro-architectural space, we are based on the same concept as Christian Monroy [5]. Cristian Monroy pointed out that natural lighting should be included in the space to promote concentration and produce more comfort Space. Looking outside can keep in touch with the natural space, thereby reducing stress; high ceilings to create a large space and bring freedom to users in the project; and finally, close-distance disease, according to Grecia 
Guzmán Martínez, a graduate student in psychology [ The study of 6] is the study of the relationship and communication with other people through space and the distance established between us and things around us.

The second integrated element of the concept is the creation of a community. According to the work of Ezequiel Ander-Egg, he refers to a collective field in his famous book "Methodology and Practice of Community Development" [7] and is represented by its "generic" name. Apply this concept to specify certain aspects shared by a group of people whose emotions and possessions also interact. According to the author, this is what makes people's perceived relationships and networks of common bonds psychologically recognized by their communities.

After understanding the meaning of the author's Ander-Egg community, it can be determined that the creation of the community was designed for users in the Montessori project through design spaces, which allow users to have different activities together. So that children can have sensory experience with people around and promote social interaction. Similarly, a space is designed for parents to create an area with family connection or family connection with the school, thereby gaining users' trust in our project. Finally, holiday spaces and meeting places are also added to the elements that create the community, so as to be able to accommodate any type of situation, thus completely supplementing the community environment.

The third element considered in the Montessori project is universal design. According to the Universal Design Center [8], the main goals are through reasonable use, flexibility of use, simple and intuitive space, area of perceivable information, fault tolerance, low-strength actions and space, and adequate methods and use [9]

Universal design is considered for the design of the Montessori Project in order to have such a variety of areas that are accessible to anyone visiting the site. [9] The spaces are generated without difficulties so that the flow and activities can flow in the best possible way around everyone and in this way amplify diversities based on physical and functional characteristics that constitute people with different cultures, languages, etc. According to the same research from the Center for Universal Design, it is stated that universal design simplifies people's lives, and it is for this same reason that it is also a fundamental element considered in the Montessori Project.

The fourth and last element is that of Sustainability, which according to the Center for Global Change and Sustainability, A.C. [10], is the process that seeks to find a balance between the environment and the daily use of natural resources. This element is used to benefit the environment with the use of sustainable energy, reduction of areas and free spaces. The designs implemented within the Project use sustainability using green areas inside and outside the project. This too, in order to have more attractive spaces and to establish a connection from the interior to the exterior of the design.

Architectural design goes hand in hand between various elements, providing everyone with space, public space, sustainable space, and most importantly, providing diversified and multi-purpose spaces to provide more internal and external wealth. It is understandable that these elements serve as "components" in order to provide final recommendations for the Montessori project. However, the same architectural design is supplemented by the use of technology to generate an intelligent building that responds to the bioclimatic conditions of the environment to provide the final touch for our project: the architectural appearance.

\section{$4 \quad$ Intelligent buildings and the Architectural Skin}

An intelligent building is defined as a "responsive architecture" that provides every occupant with productive, cost-effective and environmentally approved conditions through a continuous interaction among its basic elements which include places, process, people, etc. [11]

This kind of intelligence mentioned in construction is the future of the construction industry [12]. Architect Osama Omar (Beirut Arab University, Dr. Tareek Gdedah, Omar Farokh Street) mentioned this and emphasized that its main goal is to reduce energy consumption by adopting sustainable design energy-saving strategies, thereby reducing expenses.

The use of different factors contributes to the design of intelligent buildings [12]. Energy, environment, flexibility, cost-effectiveness, comfort, efficiency, safety, culture and technology are the elements that can be perfectly used to generate smart buildings, which can help solve different environmental problems and provide innovative ones.

Intelligent buildings can be designed and composed of distinctive factors (as mentioned above). The one that we decided to include in our design is the Architectural Skin.

"In the body and in nature, the skin, elastic and flexible, represents the filter and the connection with the world. Through the expressions of the skin and the body's gestures, interpersonal relationships are established and spaces are defined "Trovato, G. (2007).

The exterior wall of a building is the first element located between public and private or between exterior and interior [13]. The facade is shown as the outer skin or envelope structure of the building and can also be used as an element to give the design its own 
personality through different textures, colours and materials.

Over the years, the building envelope has undergone evolution, resulting in freedom of expression, because architects have generated flexible forms and autonomy through different concepts and technical processes, configuring them as somewhat independent elements [13]. Nowadays, these shells can be different in design and materials, making them favored in terms of comfort, environmental settings and energy consumption.

"Contemporary architecture substitutes the idea of a facade for that of skin: an outer layer that mediates between the building and its surroundings. Not a neutral elevation, but an active, informed membrane; communicative and in communication. " (Manuel Gausa, the metapolis dictionary of advanced architecture)

The architectural skin can have different objectives in order to achieve an intelligent and technological project [13]. Several of them can be acoustic insulation, thermal insulation, technological expressions, etc. These skins, because they are responsive, usually change their appearance as they adapt to the requirements and information of the context. Thanks to technology, its adaptation is achieved and the interaction of users with the space is achieved, where the object, subject, meaning and use are linked.

\subsection{Case study: Amsterdam Railway Bridge Cafe- Restaurant by Architekten Cie.}

This cafe is located on the IJ River in Amsterdam in 1922, the bridge number is $19 \mathrm{~S}$ [14]. This bridge is used as a modern railway connection between Westelijk Stationeiland and Westerdokseiland. Its location and panoramic views allowed the city of Amsterdam to combine architectural and historical design to create a café restaurant.

The building is pure transparent glass, which is very suitable for existing bridges. Its glass façade is entirely composed of pivot windows, all of which can be opened for better external connections. [14]

The volume is defined by its architect as "honest" and "pure" in its details. This architectural skin (window) improves on the principles of modern and pure boxes, and also introduces elegant qualities and undulating movements on its paneled facade. [14]

The Railway Cafe-Restaurant with its facade allows users to open and close interactive windows, which means that its movement has been de-energized. [14] This helped us get the idea of Montessori project proposal and innovate its function.

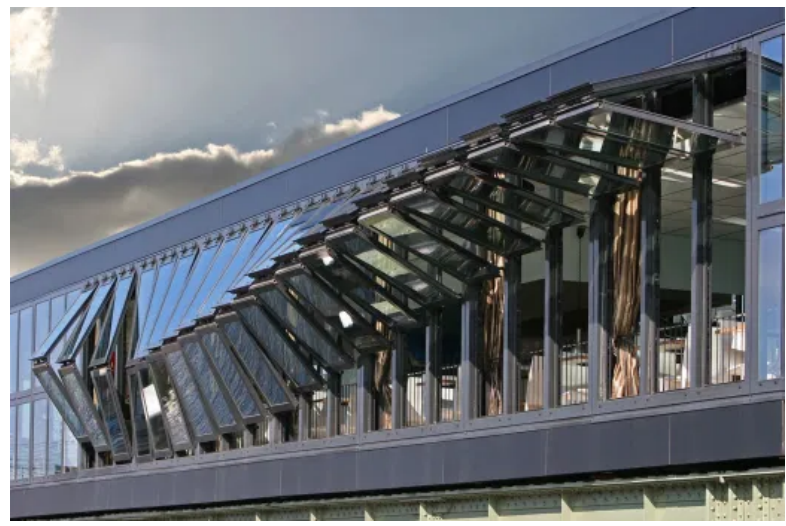

Fig 2. Glazed facade at Cafe-Restaurant Amsterdam.

\subsection{Architectural Skin in the Montessori Project}

In the Montessori project, a responsive architectural appearance was used to achieve internal and external comfort. It is designed to provide a comfortable space for the background from the appearance to the project, and to produce a comfortable interior area to enjoy its interior space more.

The smart skin or envelope used in our project is composed of vertically running aluminium windows to complement the verticality of the design using SageGlass glass. This type of glass was implemented in the project because it follows the concept of Eduardo Souza, an architect and urban planner graduated from the Federal University of Santa Catarina (UFSC) [15], which is an electrochromic glass sold by Saint-Gobain When tension is applied to the glass plate, it changes colour. For colour changes, an intelligent control system is used, which uses a series of sensors to automatically colour according to light conditions and can be changed according to user commands and needs, thereby reducing the energy consumption of internal lighting. The project allows to change the intensity of light and ultraviolet rays transmitted to the interior to improve the interior comfort of the project.

With the use of technology, it uses a motorized mechanism responsive to sunlight which allows these windows to fold or expand by folding just in half. When the sun touches the architectural skin, it will be completely closed so that the aluminium and glass used help control the interior temperature and in the same way, saving energy or the use of facilities such as air conditioning for a greater comfort of the areas, which makes the smart building a sustainable building.

When the sun is not on the facade, it will open or bend so that it can be connected to the exterior of the building. Likewise, it allows natural light, ventilation and temperature to enter, thereby giving a sense of fusion between the inside and the outside. It is worth mentioning that when folding them, due to their size, a parasol can be produced that can also support the 
project in terms of shadow generation and lighting games.

This skin is intelligent since its mechanism works hand in hand with sustainability and neuro architectural well-being. Bioclimatic criteria are taken into account to understand the element also working as energy saving, since depending on the position of the sun it can adapt and reduce the heat inside the building or the light inside it. This thanks to its function as a technological and intelligent adaptive umbrella, resulting in an architectural skin suitable for the objective and well-being of the Montessori Project.

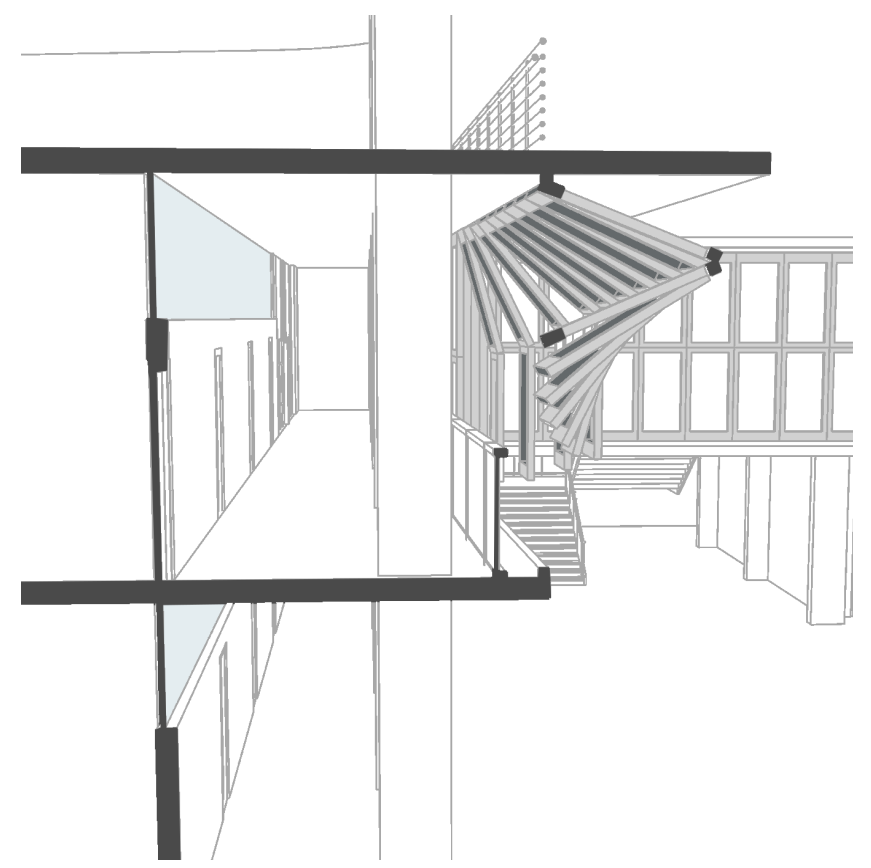

Fig 3. Folded motorized mechanism.

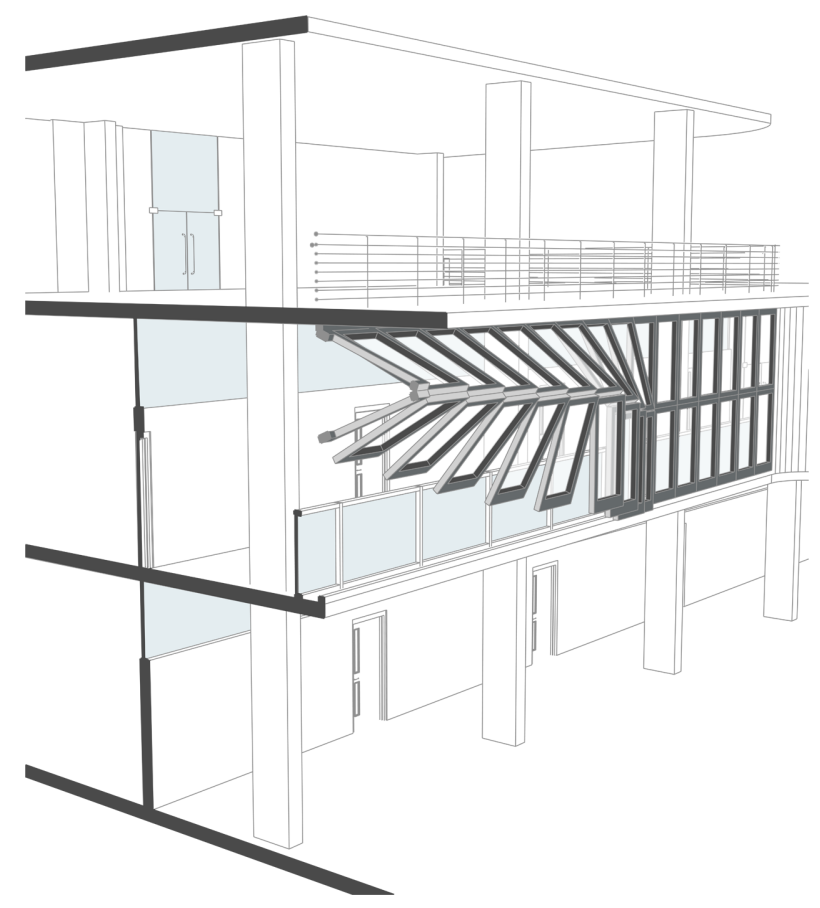

Fig 4. Active Architectural Skin of the Montessori Project according to the sunlight of the site.

\section{Conclusion}

Each building has its own essence, design, purpose and idea. These factors are determined by a process of analysis which studies elements that comprehend a building.

To start any design, architects always make a profound analysis to define that purpose [16]. In order to know what design to include in your design, architects make this analysis simplifying things into different "buckets" so that there are more details to fulfil the analysis.

The character of a building is composed of these studies. This is why every building differs from each other because their locations, their uses and their context are never the same.

In our analysis, we decided to study the Montessori Method, which served as a base topic to establish our objectives and actually see why we need to design things the way they were proposed.

The Montessori method is a technique that makes everyone's life simple and easy. This is why we decided to emphasize our project in the process, because our goal is to provide space for everyone, not only for the students assisting the project, but also for those who visit the area for any reason.

After a correct and in-depth analysis, we determined the purpose of the basic concepts and made them look 
like "ingredients" or "steps" to be followed, thus creating the correct Montessori project for students and visitors.

The designs that are used at the Project go further away than just designing spaces. Using all the materials or ingredients, we get users and visitors to feel spaces and use their own emotions to feel part of the area where they are. People feel secure, they feel emotions by just passing through an area and connect physical with emotional thoughts and create memories, something that someone will remember. That is our goal by studying, analysing and applying these factors at our project.

We conclude that these are elements that are really important at the design process or idea, but it doesn't mean there are no other ways or solutions to get where we want to get. In this case, we combined emotional, physical and technological features to comprehend our building, all with the use of the architectural skin.

An intelligent building will always bring positive factors towards a project. It involves sustainable elements that helps with the major problem of contamination in the environment and also helps with comfort designs.

The Montessori Method combined with technological techniques is optimal for solving problems. Thanks to the base concepts and technology, an implementation of an intelligent-sustainable-motorized facade or skin is implemented at the design.

This responsive design takes advantage of bioclimatic factors such as sun and wind to regulate feels and sensorial spaces inside the project. It also allows ventilation to get combined with the project and form a more-natural environment for it. As we mentioned, this technology helps improve the neurological feelings at the building besides being a sustainable element.

We can conclude that the combination of all these past concepts with the technology brings us to a very adaptive project for everyone. The architectural skin in any building, but in this case in educational buildings, has positive objectives which provides optimal and qualified spaces for students from an early age for a better learning environment and process.

Inside-outside is always present in the project, which produces sensory sensations and improves the user's sense of belonging to their surroundings. This same connection generates strong feelings and emotions with nature and helps encourage visitors to take care and protect the project.

The combination of all these elements and all investigations provides a gratifying final project not only for educational buildings but also for any architectural element. It is important to know that technology, sustainability and sensory factors are factors that must be considered for a better place creation process that includes everyone and improves comfort, sustainability and architectural design. 


\section{References}

1. A. (2016a, enero 27). Carácter de un edificio. Arkiplus.

https://www.arkiplus.com/caracter-de-un-edifi cio/

2. Martínez, G. G., \& Guzmán Martínez, G. (2020, 23 noviembre). ¿Quién fue Maria Montessori? Biografía de esta educadora y pedagoga. Psicología y Mente. https://psicologiaymente.com/biografias/maria -montessori

3. El método Montessori. (2020). FAMM. https://www.fundacionmontessori.org/metodo -montessori.htm

4. Diseño arquitectónico: definición, tipos y ejemplos. (2020).

$\mathrm{MCH}$.

https://www.mchmaster.com/es/noticias/disen o-arquitectonico-definicion-tipos-y-ejemplos/

5. Monroy, C. (2020, 6 julio). ¿Qué es la neuroarquitectura? Cristian Monroy. https://www.cristianmonrov.com/2020/07/que -es-neuroarquitectura.html

6. Martínez, G. G., \& Guzmán Martínez, G. (2020a, noviembre 23). Proxémica: qué es y cómo nos ayuda a entender los espacios. Psicología y Mente. https://psicologiaymente.com/social/proxemic a

7. APUNTES SOBRE DESARROLLO COMUNITARIO. (2020). Ezequiel Ander-Egg.

https://www.eumed.net/libros-gratis/2011d/10 46/concepto comunidad.html

8. Center for Universal Design, 1997; Story, Mueller, Mace, 1998; INTECO, 2008: cap. 2.1; Fundación Sidar

9. Usuario, S. (2020). Términos Adecuados para Referirnos a Personas con Discapacidad. Ronald L. Mace. http://www.webmati.es/index.php?option=co $\underline{\mathrm{m} \text { content\&view }=\text { article \&id=54:las-ideas-fun }}$ damentales-del-diseno-universal\&catid=15\&It $\underline{\underline{e m i d}=160}$

10. Smartia Group. (2020). ¿Qué es Sustentabilidad? | CCGS. CCGS. http://ccoss.org/sustentabilidad/

11. What is an intelligent building? Analysis of recent interpretations from an international perspective. (2020). Taylor \& Francis. https://www.tandfonline.com/doi/full/10.1080 100038628.2015 .1079164

12. Intelligent building, definitions, factors and evaluation criteria of selection. (2018, 1 diciembre). ScienceDirect. https://www.sciencedirect.com/science/article/ pii/S1110016818300887

13. Segura, R. (2020) Pieles Arquitectónicas: de la fachada a la encolvente. Recuperado de: https://cdigital.uv.mx/bitstream/handle/12345
6789/38970/RUA7p28.pdf?sequence $=1$ \&isAll owed $=$ y

14. Hilal, A. (2017, 22 agosto). Cafe-restaurant OPEN, Amsterdam / by de Architekten Cie. Architecture List. http://www.architecturelist.com/2011/04/01/ca fe-restaurant-open-amsterdam-by-de-architekt $\underline{\text { en-cie/ }}$

15. Souza, E. (2020, 2 octubre). Fachadas inteligentes de vidrio: edificios que se adaptan al clima a través de su piel. ArchDaily México. https://www.archdaily.mx/mx/925327/fachada s-inteligentes-de-vidrio-edificios-que-se-adapt an-al-clima-a-traves-de-su-piel

16. A process of analysis and synthesis gives architects and designers. (2020). Building Design $+\quad$ Construction. https://www.bdcnetwork.com/blog/process-an alysis-and-synthesis-gives-architects-and-desi gners-information-they-need-create 